\title{
PROGRESSION OF SMALL, IRREGULAR OPACITIES IN CHEST RADIOGRAPHS OF FORMER ASBESTOS WORKERS
}

\author{
BEATA ŚWIĄTKOWSKA, WOJCIECH SOBALA, and ZUZANNA SZUBERT \\ Nofer Institute of Occupational Medicine, Łódź, Poland \\ Department of Occupational and Environmental Epidemiology
}

\begin{abstract}
Objectives: Pulmonary parenchymal changes appear many years after the start of exposure to asbestos and their progression has been observed to continue many years after cessation of the exposure. The aim of the present analysis is to assess the risk of progression of radiological changes in the respiratory system, based on long-term follow-up of groups of workers occupationally exposed to asbestos dust. Materials and Methods: The analysis included 3144 individuals voluntarily applying for a medical examination in 2000-2010, who had performed at least two radiographs of the chest. Probability of progression in subsequent studies was based on the evaluation of radiographs for the presence of small, irregular type s, t, u opacities in the parenchymal lung tissue with profusion categories as specified in the classification of ILO, 1980. Multistate hidden Markov model was used in the statistical analysis. Results: In the group of patients, small irregular opacities with a profusion of 1/1 or higher occurred in $640(20 \%)$ patients in the first examination, and in $918(29 \%)$ patients in the last examination. No parenchymal changes were observed in $1360(43 \%)$ patients in the first examination (opacity profusion category 0/0), and in $645(20 \%$ ) patients in the last examination. The risk of progression of radiographic changes in former workers of asbestos processing plants is higher in smokers, from profusion category 0 to 1 - by $30 \%$ $(\mathrm{HR}=1.30,95 \% \mathrm{CI}: 1.15-1.47)$, from profusion category 1 to 2 - by $50 \%(\mathrm{HR}=1.50,95 \% \mathrm{CI}: 0.92-2.45)$. The risk of progression of parenchymal changes decreases in the workers employed in subsequent calendar years: for category changes from 1 to 2, the decrease is nearly $40 \%$ for every 10 years of subsequent employment (HR $=0.60,95 \%$ CI: $0.45-0.80$ ). The probability of the progression increases with longer latency period: for change of category from 1 to 2 , the increase is about $20 \%$ ( $\mathrm{HR}=1.19,95 \%$ CI: 1.00-1.42) per 10 years of employment for blue collar workers. The risk of the 1 to 2 category progression is significant, nearly 2.5 -fold higher in the workers employed in the asbestos-processing textile industry. Conclusions: Our results show that the risk of progression of pulmonary parenchymal fibrotic processes was higher in the smokers, workers employed during the earlier calendar years of the discussed period, those with longer latency period, blue collar workers involved directly in the production processes, and employees of the asbestos cement and/or textile industries.
\end{abstract}

Key words:

Chest X-ray examination, Small opacities, Long-term observation, Asbestos processing plants, Profusion score

\footnotetext{
This work was performed under the research item IMP 10.3: "Progression of asbestos-related changes in the respiratory tract based on long-term clinical follow-up of a cohort of people employed in asbestos processing plants”. Project leader: Beata Świątkowska, MD.

Received: June 6, 2012. Accepted: October 26, 2012.

Address reprint requests to B. Świątkowska, Nofer Institute of Occupational Medicine, Department of Occupational and Environmental Epidemiology, św. Teresy 8 , 91-348 Łódź, Poland (e-mail: beata_sn@imp.lodz.pl).
} 


\section{INTRODUCTION}

Asbestos is recognized as a substance with proven carcinogenic activity. Inhalation of asbestos fibres can cause the development of serious respiratory diseases, including asbestosis (parenchymal fibrosis of lung tissue). Asbestos fibres may persist in the lung tissue for a long time and the fibrotic process may become evident many years after cessation of exposure [1].

The diagnosis of asbestosis, especially in its early stages, is difficult because of the lack of specific clinical symptoms of the disease. The clinical diagnosis of asbestosis relies on the results of radiological examinations. Changes in the lungs, visible in X-ray images in the form of small, irregular opacities of different thicknesses, representing varying degrees of advancement, are of greatest diagnostic value. Type and category of pneumoconiotic quantitative (profusion) changes in the lungs are classified using the "Guidelines for the use of ILO International Classification of Radiographs of Pneumoconioses" [2].

The purpose of this paper is to determine the risk of progression of fibrotic processes in the pulmonary parenchymal tissue (changes in profusion of small irregular opacities) with reference to the duration (years) of employment, calendar period of employment, time since beginning of exposed employment (latency), type of processed asbestos, employment as a worker involved in production process, gender, age, and smoking habit in former workers of asbestos processing plants.

\section{MATERIALS AND METHODS}

\section{Study design}

Since 2001, Poland implemented a program of unified, periodic medical examinations, known as the Amiantus Programme, for former workers of asbestos processing plants. Workers of 28 former asbestos processing plants who were employed in these plants until 1997 (the year since which the use of asbestos in Poland has been banned) have been included in that project. Voluntary periodic medical examinations intended to evaluate the respiratory system were carried out by the 13 provincial centres of occupational medicine territorially pertinent to the place of business of the former plants [3-5].

The study group included people voluntarily applying for a medical examination under the Amiantus Programme in 2000-2010, who underwent at least two full-size chest radiographs, evaluated by a specialist radiologists and recorded on a pneumoconiosis radiograph reading form according to the ILO classification (1980). The selected group of 3144 individuals constituted $46 \%$ of all patients who participated in the Amiantus Programme.

The study population consisted of workers of asbestos processing plants who, according to the manufactured products and the production technologies, were grouped as follows: asbestos-cement plants (employees of these plants accounted for $55.3 \%$ of those included in the analysis), textile plants (13.6\%), sealing products plants (9.4\%), waterproofing products plants $(9.4 \%)$, friction products plants $(8.4 \%)$ and other plants.

Those other plants comprised small workshops or cooperatives employing a dozen or less people and those in which asbestos was used only as an element of the technological process. The employees of those businesses accounted for less than $4 \%$ of those included in the analysis.

For the purposes of the Amianus Programme, unified strategy of comprehensive examinations and their documentation had been developed. Information on work history (job, workplace, length of service, period of employment), and smoking history was obtained from the questionnaire (examination card) by the physician performing the examinations.

\section{Chest radiography}

Chest X-ray is the basic diagnostic test for workers included in the preventive examination programme, former employees of plants processing asbestos. Radiographs of the 
chest of people included in the programme were sent by the centres performing the tests to the project coordinator for assessment and coding of the pneumoconiotic changes in the radiograph reading forms according to the ILO1980 classification. This assessment and coding was done by two doctors experienced in coding and radiological diagnosis of changes in the lungs.

Progression of parenchymal changes was determined from consecutive readings of standard radiographs with reference to the small, irregular (type s, t, or u) opacities evaluated according to 12-step profusion scale. For the purpose of the analysis, the 12-step optical profusion scale of X-ray changes was aggregated to obtain a three-item scale: 0 (categories $0 / 0,0 / 1), 1(1 / 0,1 / 1,1 / 2)$ and 2 (2/1 and higher).

\section{Statistical analysis}

For statistical inference two-sided tests have been used. Significance level 0.05 has been adopted. We have used multinomial regression to test time trends in X-ray quality and symmetry test to verify the general hypothesis about disease progression between first and last observation in the study.

In order to model the course of diseases we have used multi-state hidden Markov models with continuous time. We have assumed the disease under study to be irreversible, so the transition intensities corresponding to recovery were assumed to be 0 . We have also assumed that workers had no parenchymal opacities at the date of first employment. We have added one data point for each worker for the time of first employment (zero latency).

Explanatory variables for both the rates of transition between underlying stages and the probabilities of misclassification were included into the model. We have included X-ray quality and age at examination as predictors of misclassification. In all presented models, latency has been included as predictor of transition intensities.

We have encountered failure of convergence for models with seven states after inclusion of predictors, so we have combined adjacent states to simplify the model. We have used the Hessian matrix to calculate standard error of estimates and its confidence intervals.

All statistical analyses were conducted using $\mathrm{R}$ and $\mathrm{msm}$ package was used to fit the multistate Markov model [6,7].

\section{RESULTS}

The analysis comprised 3144 people (including $36.6 \%$ women). People aged 51-60 (41.7\%) were the most numerous group of people reporting for prophylactic examinations, while the people younger than 50 constituted $27.9 \%$ of the group. Persons who declared current smoking accounted for $22.4 \%$ of the analysed group, and the proportion of smokers was lower among those employed in earlier calendar years and for longer time of service. Employees commencing work in asbestos processing plants in 1966-1975 dominated among those included in the analysis. Most people reporting for the examinations worked for more than 16 years in asbestos processing plants. The majority of those employees started working at those plants when they were younger than 30 . Among those included in the analysis, those working in asbestos-cement factories (55.3\%) were the largest group of people. The proportion of people working in production departments was 57.2\%. For most patients (45.6\%), the time since the moment of employment until the first X-ray examination of the chest was 16-30 years; the time shorter than 15 years was recorded in only $7.2 \%$ of the surveyed former workers of asbestos processing plants. A considerable proportion of individuals included in the analysis X-rayed twice $(34.4 \%)$ or thrice $(21.6 \%)$. For most people included in the analysis, the interval between the first and last examination ranged from 5 to 7 years (Table 1).

Among the total number of analyzed chest radiographs, $83.6 \%$ were the highest quality images, $14.1 \%$ images were second grade of quality and $2.3 \%$ of the 
Table 1. Description of the study population

\begin{tabular}{|c|c|c|}
\hline \multirow{2}{*}{ Characteristics } & \multicolumn{2}{|c|}{ Respondents } \\
\hline & $\mathrm{n}$ & $\%$ \\
\hline Total population & 3144 & 100.0 \\
\hline \multicolumn{3}{|l|}{ Period of starting work (calendar years) } \\
\hline $1945-1965$ & 543 & 17.3 \\
\hline 1966-1975 & 1241 & 39.4 \\
\hline 1976-1985 & 984 & 31.3 \\
\hline 1986-1998 & 376 & 12.0 \\
\hline \multicolumn{3}{|l|}{ Age at time of first radiograph (years) } \\
\hline$\leq 50$ & 876 & 27.9 \\
\hline $51-60$ & 1311 & 41.7 \\
\hline $61-70$ & 684 & 21.7 \\
\hline$\geq 71$ & 273 & 8.7 \\
\hline \multicolumn{3}{|l|}{ Type of asbestos product manufacture } \\
\hline asbestos-cement & 1738 & 55.3 \\
\hline textiles & 429 & 13.6 \\
\hline sealing & 294 & 9.4 \\
\hline waterproofing & 297 & 9.4 \\
\hline friction & 263 & 8.4 \\
\hline others remaining & 123 & 3.9 \\
\hline \multicolumn{3}{|l|}{ Duration of employment (years) } \\
\hline$\leq 5$ & 793 & 25.2 \\
\hline $6-15$ & 1061 & 33.8 \\
\hline$\geq 16$ & 1290 & 41.0 \\
\hline \multicolumn{3}{|c|}{ Time since employment till the first examination (years) } \\
\hline$\leq 15$ & 226 & 7.2 \\
\hline $16-30$ & 1433 & 45.6 \\
\hline $31-45$ & 1349 & 42.9 \\
\hline$>45$ & 136 & 4.3 \\
\hline \multicolumn{3}{|l|}{ Smoking status } \\
\hline never & 1258 & 40.0 \\
\hline ex-smokers & 1183 & 37.6 \\
\hline current smokers & 703 & 22.4 \\
\hline \multicolumn{3}{|l|}{ Time between X-ray examinations (years) } \\
\hline $1-2$ & 714 & 22.7 \\
\hline $3-4$ & 800 & 25.5 \\
\hline $5-7$ & 1390 & 44.2 \\
\hline$>7$ & 240 & 7.6 \\
\hline
\end{tabular}


Table 1. Description of the study population - cont.

\begin{tabular}{lrr}
\hline & \multicolumn{2}{c}{ Respondents } \\
\cline { 2 - 3 } & Characteristics & $\mathrm{n}$ \\
\hline Categories of small, irregular opacities & 1360 & \\
$0 / 0$ & 762 & 43.2 \\
$0 / 1$ & 382 & 24.2 \\
$1 / 0$ & 437 & 12.2 \\
$1 / 1$ & 150 & 13.9 \\
$1 / 2$ & 53 & 4.8 \\
$2 / 1-2 / 3$ & 53 & 1.7 \\
\hline
\end{tabular}

radiographs were rated as third grade of technical quality. Radiographs of insufficient technical quality were excluded from the analysis. In subsequent years of the prevention programme, there was a significant favourable trend of decline in the number of images of 2 and 3 grade of technical quality (Table 2).

In the study group of 3144 patients, $1360(43.2 \%)$ had no parenchymal changes within the small, irregular opacities in the chest X-ray made during the first examination, (opacity profusion category $0 / 0$ ). During the last examination, these changes were not detected in 645 (20.5\%)

Table 2. Technical quality of chest radiographs related to the year of examination

\begin{tabular}{lcccc}
\hline \multirow{2}{*}{$\begin{array}{c}\text { Year of X-ray } \\
\text { examinations }\end{array}$} & Total & \multicolumn{3}{c}{ Film quality (\%) } \\
\cline { 3 - 5 } & (n) & grade 1 & grade 2 & grade 3 \\
\hline 2002 & 806 & 73.9 & 22.6 & 3.5 \\
2003 & 1811 & 74.1 & 21.6 & 4.3 \\
2004 & 1747 & 77.6 & 19.6 & 2.6 \\
2005 & 1680 & 77.3 & 19.6 & 3.0 \\
2006 & 1653 & 81.6 & 16.1 & 2.3 \\
2007 & 1601 & 85.6 & 12.8 & 1.6 \\
2008 & 1440 & 89.3 & 9.0 & 1.7 \\
2009 & 1609 & 94.3 & 4.5 & 1.1 \\
2010 & 1458 & 98.2 & 1.4 & 0.4 \\
Total & 13828 & 83.6 & 14.1 & 2.3 \\
p value (trend) & - & - & $<0.001$ & $<0.001$ \\
\hline
\end{tabular}

patients. Small, irregular opacities with a profusion of $1 / 1$ and above were noted in 640 patients $(20.3 \%)$ during the first examination, and in 918 (29.2\%) patients during the last examination. More advanced changes were observed in the last examination in 1489 patients (47.4\%). These changes were observed for all periods of latency. In the group of people with the latency period up to 15 years, during the first examination, the proportion of patients with radiographic changes category $1 / 1$ or higher was $9.7 \%$, while the corresponding proportions for patients with latency period of 16-30 years and over 30 years were $13.1 \%$ and $29.0 \%$, respectively. These changes were statistically significant $(\mathrm{p}<0.001)$ (Table 3$)$ for all latency categories. The women, compared with men, had a lower risk of progression from low-profusion opacity category 0 to 1 between the consecutive X-ray examinations $(\mathrm{HR}=0.80 ; 95 \%$ CI: 0.71-0.90) and a higher probability of deterioration in the radiographic evaluation from category 1 to 2 (HR $=1.15$; 95\% CI: 0.71-1.87) (Table 4).

The risk of progression of parenchymal changes in former workers of asbestos processing plants is higher in smokers. For a change from category 0 to 1 , the risk is higher by $26 \%(\mathrm{HR}=1.26 ; 95 \% \mathrm{CI}: 1.12-1.43)$ and for profusion category from 1 to 2 it is higher by $16 \%$ (HR $=1.16$; $95 \%$ CI: 0.71-1.89).

The risk of progression of parenchymal changes in former employees of asbestos-processing plants decreases at later 
Table 3. Prevalence of categories of small, irregular opacities in chest radiographs among study population by time since employment till the first examination (years)

\begin{tabular}{|c|c|c|c|c|c|c|c|c|c|}
\hline \multirow{3}{*}{$\begin{array}{c}\text { First } \\
\text { examination }\end{array}$} & \multicolumn{8}{|c|}{ Opacity subcategories (n) } & \multirow{3}{*}{ Total } \\
\hline & \multicolumn{8}{|c|}{ most recent radiographic examination } & \\
\hline & $0 / 0$ & $0 / 1$ & $1 / 0$ & $1 / 1$ & $1 / 2$ & $2 / 1$ & $2 / 2$ & $2 / 3$ & \\
\hline \multicolumn{10}{|c|}{ all years* } \\
\hline $0 / 0$ & 493 & 493 & 241 & 114 & 15 & 2 & 2 & 0 & 1360 \\
\hline $0 / 1$ & 115 & 289 & 198 & 134 & 21 & 3 & 2 & 0 & 762 \\
\hline $1 / 0$ & 26 & 91 & 136 & 102 & 20 & 3 & 4 & 0 & 382 \\
\hline $1 / 1$ & 11 & 41 & 75 & 233 & 85 & 11 & 8 & 0 & 437 \\
\hline $1 / 2$ & 0 & 4 & 11 & 49 & 60 & 8 & 17 & 1 & 150 \\
\hline $2 / 1$ & 0 & 0 & 1 & 3 & 2 & 4 & 3 & 1 & 14 \\
\hline $2 / 2$ & 0 & 0 & 1 & 8 & 9 & 2 & 17 & 1 & 38 \\
\hline $2 / 3$ & 0 & 0 & 0 & 0 & 0 & 0 & 0 & 1 & 1 \\
\hline Total & 645 & 918 & 663 & 643 & 185 & 33 & 53 & 4 & 3144 \\
\hline \multicolumn{10}{|c|}{ time since start of employment till the first examination 15 years* } \\
\hline $0 / 0$ & 72 & 46 & 17 & 6 & 0 & 0 & 0 & 0 & 141 \\
\hline $0 / 1$ & 18 & 16 & 12 & 3 & 0 & 0 & 0 & 0 & 49 \\
\hline $1 / 0$ & 0 & 4 & 3 & 5 & 2 & 0 & 0 & 0 & 14 \\
\hline $1 / 1$ & 0 & 2 & 3 & 8 & 2 & 0 & 0 & 0 & 15 \\
\hline $1 / 2$ & 0 & 2 & 0 & 3 & 1 & 1 & 0 & 0 & 7 \\
\hline $2 / 1-2 / 3$ & 0 & 0 & 0 & 0 & 0 & 0 & 0 & 0 & 0 \\
\hline Total & 90 & 70 & 35 & 25 & 5 & 1 & 0 & 0 & 226 \\
\hline \multicolumn{10}{|c|}{ time since start of employment till the first examination $16-30$ years* } \\
\hline $0 / 0$ & 267 & 275 & 120 & 58 & 7 & 1 & 1 & 0 & 729 \\
\hline $0 / 1$ & 52 & 150 & 85 & 50 & 6 & 1 & 0 & 0 & 354 \\
\hline $1 / 0$ & 16 & 40 & 61 & 39 & 5 & 0 & 1 & 0 & 162 \\
\hline $1 / 1$ & 5 & 22 & 35 & 71 & 14 & 4 & 1 & 0 & 152 \\
\hline $1 / 2$ & 0 & 1 & 3 & 8 & 11 & 2 & 3 & 0 & 28 \\
\hline $2 / 1$ & 0 & 0 & 0 & 0 & 0 & 1 & 1 & 0 & 2 \\
\hline $2 / 2$ & 0 & 0 & 1 & 0 & 3 & 1 & 1 & 0 & 6 \\
\hline Total & 350 & 488 & 305 & 226 & 46 & 10 & 8 & 0 & 1433 \\
\hline \multicolumn{10}{|c|}{ time since start of employment till the first examination $>30$ years* } \\
\hline $0 / 0$ & 154 & 172 & 104 & 50 & 8 & 1 & 1 & 0 & 490 \\
\hline $0 / 1$ & 35 & 123 & 101 & 81 & 15 & 2 & 2 & 0 & 359 \\
\hline $1 / 0$ & 10 & 47 & 72 & 58 & 13 & 3 & 3 & 0 & 206 \\
\hline $1 / 1$ & 6 & 17 & 37 & 154 & 42 & 7 & 7 & 0 & 270 \\
\hline $1 / 2$ & 0 & 1 & 8 & 38 & 48 & 6 & 13 & 1 & 115 \\
\hline $2 / 1$ & 0 & 0 & 1 & 3 & 2 & 3 & 2 & 1 & 12 \\
\hline
\end{tabular}


Table 3. Prevalence of categories of small, irregular opacities in chest radiographs among study population by time since employment till the first examination (years) - cont.

\begin{tabular}{lrrrrrrrrr}
\hline \multirow{8}{*}{$\begin{array}{c}\text { First } \\
\text { examination }\end{array}$} & \multicolumn{7}{c}{ Opacity subcategories (n) } & \multirow{2}{*}{ Total } \\
\cline { 2 - 8 } & $0 / 0$ & $0 / 1$ & $1 / 0$ & $1 / 1$ & $1 / 2$ & $2 / 1$ & $2 / 2$ & $2 / 3$ & \\
\hline $2 / 2$ & 0 & 0 & 0 & 8 & 6 & 1 & 16 & 1 & 32 \\
$2 / 3$ & 0 & 0 & 0 & 0 & 0 & 0 & 0 & 1 & 1 \\
Total & 205 & 360 & 323 & 392 & 134 & 23 & 44 & 4 & 1485 \\
\hline
\end{tabular}

* McNemar-Bowker symmetry test $\mathrm{p}<0.001$.

dates (later calendar years) of asbestos-exposed employment, which is particularly evident in the progression from category 1 to 2 . The probability of progression of the parenchymal changes in the X-ray images in this group of workers fell by almost $50 \%$ for each 10 years of the employment (HR $=0.55 ; 95 \%$ CI: $0.41-0.74)$.

Analysis of progression depending on the time elapsed since employment start to the first examination points to a higher risk of increased severity of parenchymal changes with longer latency period. The risk of progression from category 0 to 1 increases by $70 \%$ (HR $=1.70 ; 95 \% \mathrm{CI}$ : 1.62 1.77), while for progression from category 1 to 2 , the risk is $8 \%(\mathrm{HR}=1.08 ; 95 \% \mathrm{CI}: 0.86-1.34)$ in the period of 10 years since the moment of employment in asbestos processing plants. The analysis showed no significant influence of the duration of asbestos-exposed employment on the risk of progression of the radiographic changes.

The probability of the progression was higher in those employed at manufacturing workplaces. In this group, the risk of deterioration of parenchymal changes from the radiographic category 0 to 1 was $\mathrm{HR}=1.43$ (95\% CI: $1.27-1.61$ ), while for the change from category 1 to 2 it was almost three times higher ( $\mathrm{HR}=2.99 ; 95 \% \mathrm{CI}$ : 1.56-5.72) compared with those employed at non-manufacturing workplaces.

The probability of progression of the parenchymal changes from category 0 to 1 is highest among persons employed in the asbestos-cement products plants. Only the employees of textile mills were at nearly 3 -fold higher risk of progression from category 1 to $2(\mathrm{HR}=2.79 ; 95 \% \mathrm{CI}: 1.67-4.64)$ compared with employees of the asbestos-cement plants (Table 4).

Results of multivariate analysis taking into account the job, industry, smoking, years of employment and latency confirmed the increased risk of progression of radiographic changes in smokers compared to non-smokers and in employees of the asbestos cement and textile industries. The probability of progression of small, irregular opacities from category 1 to 2 in the textile workers is nearly 2.5 -fold higher compared to workers of the asbestos-cement plants (Table 5).

Multivariate analysis confirmed that the risk of progression of parenchymal changes is lower in workers employed in historically later periods (calendar years). There was no effect of duration of employment on the risk of progression of parenchymal changes.

Multivariate analysis of progression of the changes relative to the time elapsed since employment to the first examination points to a higher risk of progression of change from category 0 to 1 for workers performing jobs not directly associated with the manufacturing process $(\mathrm{HR}=1.83$; $95 \% \mathrm{CI}: 1.71-1.95)$. The probability of progression from stage 1 to 2 is higher in those employed in manufacturing jobs (HR = 1.19; 95\% CI: 1.00-1.42). For people employed in positions outside of direct production, the more severe were the original lesions, the less likely they were to become more severe (Table 5). 

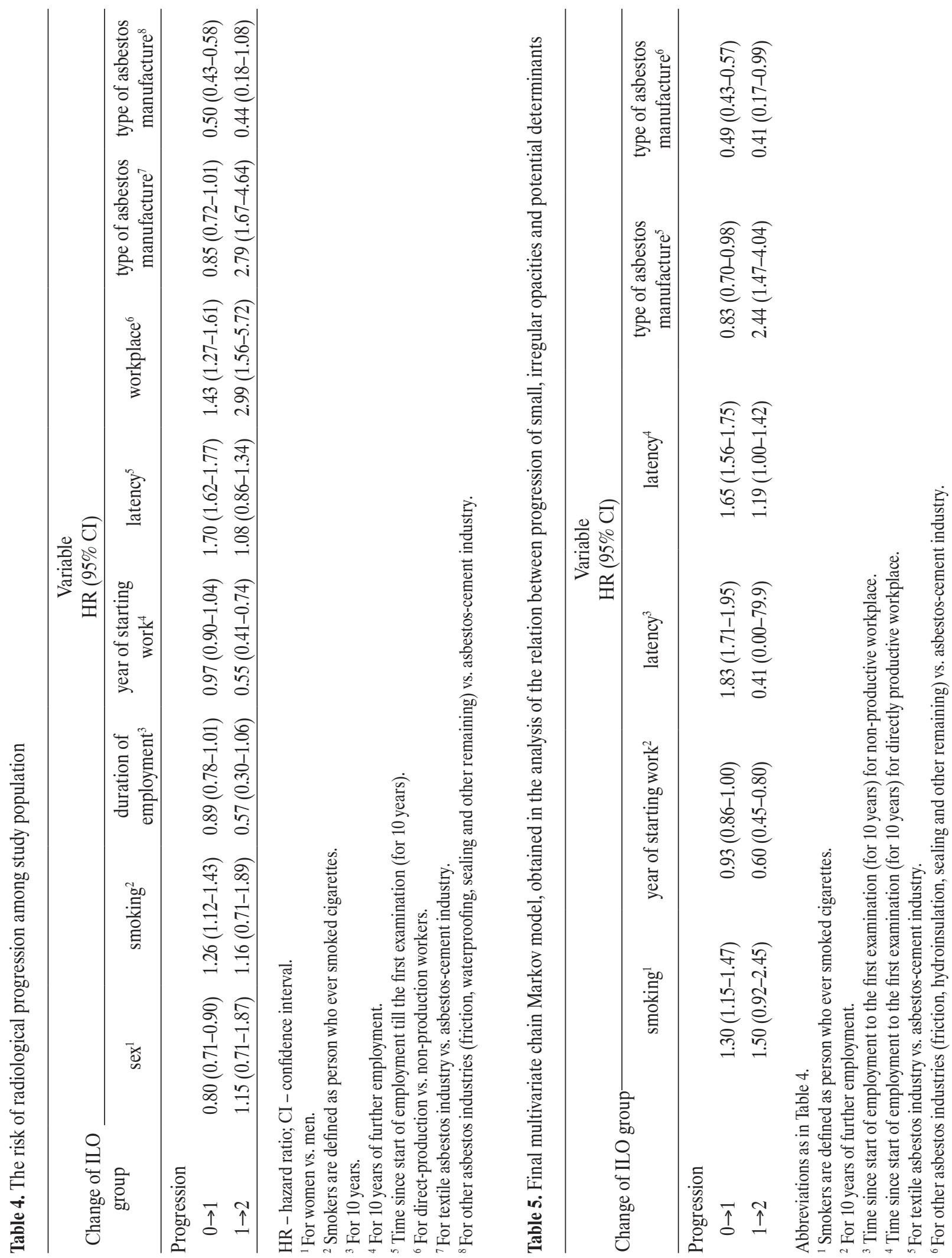


\section{DISCUSSION}

Smoking plays a major role in the development of asbestos-related diseases [8]. Impaired lung clearing mechanisms in smokers are likely to cause increased retention of asbestos fibres in the lungs and the frequent development of fibrotic changes. Higher frequency of progression of radiographic changes in smokers compared to non-smokers was also demonstrated in other previous studies $[9,10]$. A significant decrease in the probability of progression of parenchymal changes was observed in the study of people starting their employment in later calendar years. Among the group of people employed in the later period (19661985) the percentage of smokers was significantly higher compared to employees that started work in 1945-1965. Literature data indicate that low category parenchymal opacities are more often observed in smokers compared with non-smokers irrespective of the exposure to dust $[11,12]$. Thus, in people employed in the later period, smoking is the likely factor contributing to the progression of the parenchymal changes.

It has been well documented in the literature that parenchymal changes progress over many years from the start of exposure and their progress has been observed many years after the exposure [13-15]. The risk of progression rises with longer time elapsed from the exposure to the first examination. The relationship between the progression of parenchymal changes and latency has been confirmed also by observations of other authors $[9,16]$.

The analysis showed a higher risk of progression of more advanced changes (opacity category from 1 to 2 ) in people employed in manufacturing jobs, compared with those not involved directly in the production process. Despite the higher risk of statically significant progression of category 0 to 1 among those working in non-production positions with increasing latency period, this difference is small from the practical point of view.

An increased risk of progression of parenchymal changes was observed in workers of asbestos-cement industry, compared with other branches of the asbestos-processing industry. The risk of progression from category 1 to 2 changes is significantly higher in those employed in the textile industry. These differences may be due to hygienic conditions, higher content of asbestos in the textile products, and hence greater likelihood of progression to more advanced radiographic changes. It has been well documented in the literature that total dust concentration plays a major role in the determination of the risk of category $\geq 1 / 1$ parenchymal lung opacities [17].

The results reported above have certain limitations. First of all, the patients reported in the results had to spontaneously decide to participate both in the first and the subsequent examinations. Thus, selection of participants to the first and the subsequent examinations may be due to a desire to know the diagnosis of the disease, higher sensitivity, or experiencing more severe respiratory symptoms. The results relate to the asbestos processing workers whose exposure was relatively well documented, in contrast to other plants such as repair plants, shipyards, and other professional groups, such as construction workers. The study was prospective, and the subjects were workers enrolled to the study after cessation of the exposure. Unfortunately, the workers did not have baseline chest radiographs taken at the start of their work for comparison. However, the average age of the subjects at the start of their professional career was approximately 26 years. There is, therefore, a low probability of their earlier occupational exposure to asbestos or other dusts.

Another limitation of the study is that it applies only to the changes observed in the $\mathrm{X}$-ray images assigned to the category designated by the reference images according to ILO classification, which is not synonymous with the presence of interstitial changes as such [18].

Despite the limitations indicated above, the study points to the risk of progression of fibrotic processes in the pulmonary parenchymal tissue relative to some factors. The study concerns a large number of employees examined nationwide 
according to normalized criteria of standard procedures. The programme has been subject to strict rules of methodology and the test procedures take into account international experience and current experts' recommendations on organizing and conducting this type of prevention programmmes aimed at detecting asbestos-related diseases [19,20].

The multi-state hidden Markov model used in the statistical analysis made it possible to evaluate disease progression over time, taking into account the uncertainty of X-ray image evaluation. The degree of the misclassification in the model was dependent on X-ray image quality and subjects' age. Thus, it was possible to account for the effect of changes in the quality of radiographs during the implementation of the programme on the risk of the progression.

\section{CONCLUSIONS}

The results of the present study on the risk of progression of fibrotic processes in lung parenchymal tissue related to various factors lead to the following conclusions:

- the major factors increasing the risk of progression of the fibrotic changes include: earlier period (earlier calendar years) of employment, latency, and employment in plants manufacturing asbestos-cement and textile products;

- factors that significantly increase the risk of progression of profusion categories from 0 to 1 are: latency period (the longer the latency, the higher the risk of progression) and employment in plants manufacturing asbestos-cement and textile products;

- for the risk of progression of more advanced changes (profusion categories from 1 to 2), the decisive factors include earlier period (earlier calendar years) of employment and employment in plants manufacturing asbestos-cement products and asbestos textiles.

In summary, the results of the study allowed us to identify further areas of research intended to elucidate risk factors for progression of parenchymal changes in X-ray images of former employees of asbestos-processing plants. In particular, we have been able to determine the frequency of preventive examinations according to the presence of these characteristics.

\section{ACKNOWLEDGEMENTS}

The authors would like to thank all those who have collaborated in the implementation of the Amiantus Programme, in particular the physicians who have performed the periodic examinations at the provincial centres of occupational medicine and coded the changes in X-ray images.

\section{REFERENCES}

1. Szeszenia-Dąbrowska N, Świątkowska B, Szubert Z, Wilczyńska U. Asbestos in Poland: occupational health problems. Int J Occup Med Environ Health 2011;24(2):142-52. DOI: $10.2478 / \mathrm{s} 13382-011-0020-4$.

2. International Labour Office. Guidelines for the use of ILO International Classification of Radiographs of Pneumoconioses. Geneva: ILO; 1980.

3. The Act of 19 June 1997 on the ban of the use of asbestoscontaining products (unified text). J Laws 2004, No.3, item 20 as amended (Jan 12, 2004) [in Polish].

4. Szeszenia-Dąbrowska N, Szubert Z. Prophylactic examinations of former workers at asbestos processing plants: The AMIANTUS Programme. Med Pr 2002;53(6):451-6 [in Polish].

5. Szubert Z, Stankiewicz-Choroszucha B, Wrońska-Sobolewska M, Cwynar E, Dobrowolska J, Wróbel R, et al. Implementation of the AMIANTUS Programme involving prophylactic medical examinations of the former employees of asbestos processing plants. Med Pr 2011;62(5):465-72 [in Polish].

6. $\mathrm{R}$ Development Core Team. $R$ : A language and environment for statistical computing. Vienna: R Foundation for Statistical Computing; 2012 [cited 2012 May 15]. Available from URL: http://www.R-project.org. 
7. Christopher H, Jackson Ch. Multi-State Models for Panel Data: The msm Package for R. J Statistical Software 2011;38(8):1-29 [cited 2012 May 15]. Available from URL: http://www.jstatsoft.org/v38/i08.

8. Oksa P, Klockars M, Karjalainen A, Huuskonen MS, Vattulainen K, Pukkala E, et al. Progression of asbestosis predicts lung cancer. Chest 1998;113:1517-21.

9. Finkelstein MM. A study of dose-response relationships for asbestos associated disease. Br J Ind Medicine 1985;42:319-25.

10. Sluis-Cremer GK, Hnizdo E. Progression of irregular opacities in asbestos miners. Br J Ind Medicine 1989;46:846-52.

11. Weiss W. Cigarette smoking and small irregular opacities. $\mathrm{Br}$ J Ind Med 1991;48:841-44.

12. Kilburn KH, Warsaw R. Severity of pulmonary asbestosis as classified by International Labour Organisation profusion of irregular opacities in 8749 asbestos-exposed American workers. Those who never smoked compared with those who ever smoked. Arch Internal Med 1992;152:325-27.

13. Shepherd JR, Hillerdal G, McLarty J. Progression of pleural and parenchymal disease on chest radiographs of workers exposed to amosite asbestos. Occup Environ Med 1997;54(6):410-15.

14. Cugell DW, Kamp DW. Asbestos and the Pleura. Chest 2004;125(3):1103-17.
15. Larson TC, Meyer CA, Kapil V, Gurney JW, Tarver RD, Black CB, et al. Workers with Libby amphibole exposure: retrospective identification and progression of radiographic changes. Radiology 2010;255(3):924-33.

16. Jakobsson K, Strömberg U, Albin M, Welinder H, Hagmar L. Radiological changes in asbestos cement workers. Occup Environ Med 1995;52:20-7.

17. Staniszewska D, Sobala W, Szeszenia-Dąbrowska N. Epidemiological assessment of the risk of asbestos-related changes in the lungs and pleura in workers formerly exposed to chrysotile asbestos. Med Pr 2007;58(4):279-86 [in Polish].

18. Markowitz SB, Morabia A, Lilis R, Miller A, Nicholson WJ, Levin S. Clinical predictors of mortality from asbestosis in the North American Insulator Cohort, 1981 to 1991. Am J Respir Crit Care Med 1997;156:101-08.

19. Miller A. Radiographic readings for asbestosis: Misuse of science - Validation of the ILO classification. Am J Ind Med 2007;50:63-7.

20. Directive 2009/148/EC of the European Parliament and of the Council of 30 November 2009 on the protection of workers from the risks related to exposure to asbestos at work. Off J EU 2009;L330:16.

This work is available in Open Access model and licensed under a Creative Commons Attribution-NonCommercial 3.0 Poland License - http://creativecommons.org/ licenses/by-nc/3.0/pl/deed.en. 